Published in final edited form as:

Ann Intern Med. 2015 April 21; 162(8): 533-541. doi:10.7326/M14-1430.

\title{
The Population Impact and Cost-Effectiveness of Statins for Primary Prevention in Adults 75 and Older in the United States
}

\author{
Michelle C. Odden, PhD ${ }^{1}$, Mark J. Pletcher, MD, MPH${ }^{2}$, Pamela G. Coxson, PhD $^{3}$, Divya \\ Thekkethala, B.S. ${ }^{1}$, David Guzman, MS $^{3}$, David Heller, MD $^{3}$, Lee Goldman, MD, MPH $^{4}$, and \\ Kirsten Bibbins-Domingo, PhD, MD ${ }^{2,3}$ \\ ${ }^{1}$ School of Biological and Population Health Sciences, Oregon State University, Corvallis, OR \\ ${ }^{2}$ Department of Epidemiology and Biostatistics, University of California, San Francisco, CA \\ ${ }^{3}$ Department of Medicine, University of California, San Francisco, CA \\ ${ }^{4}$ College of Physicians and Surgeons, Columbia University, New York, NY, USA
}

\begin{abstract}
BACKGROUND—Over $40 \%$ of adults 75 and older are taking statins, yet there is little evidence to guide primary prevention in this population.
OBJECTIVE-To project the population impact and cost-effectiveness of statin therapy in adults aged 75 years and older.

DESIGN—Forecasting study using the Cardiovascular Disease Policy Model, a Markov model.

DATA SOURCE-Trial, cohort, and nationally-representative data sources.

TARGET POPULATION-U.S. adults aged 75-94 years.

TIME HORIZON-10 years.

PERSPECTIVE-Health care system.

INTERVENTION-Statins for primary prevention based on: 1) Low density lipoprotein cholesterol $\geq 4.91 \mathrm{mmol} / \mathrm{L}(190 \mathrm{mg} / \mathrm{dL}), 2) \geq 4.14 \mathrm{mmol} / \mathrm{L}(160 \mathrm{mg} / \mathrm{dL}), 3) \geq 3.36 \mathrm{mmol} / \mathrm{L}(130$ $\mathrm{mg} / \mathrm{dL}$ ), 4) diabetes, 5) 10-year risk score $\geq 7.5 \%$ (treat all).

\footnotetext{
Corresponding Author: Michelle C. Odden, PhD, Oregon State University, 141B Milam Hall, Corvallis, OR, 97331, Ph: 541-737-3184, Fax: 541-737-6914, Michelle.Odden@ oregonstate.edu.

Kirsten Bibbins-Domingo is a member of the United States Preventive Services Task Force (USPSTF) and current co-Vice Chair. This work does not necessarily represent the views and policies of the USPSTF.

ADDRESS FOR REPRINT REQUESTS: Michelle C. Odden, PhD, Oregon State University, 141B Milam Hall, Corvallis, OR, 97331 MAILING ADDRESSES:

Dr. Odden and Ms. T Thekkethala: Oregon State University, 141B Milam Hall, Corvallis, OR, 97331

Dr. Pletcher: UCSF Box 0560, 185 Berry Street, Lobby 5, Suite 5700, San Francisco, CA 94107-1762

Drs. Coxson, Heller, and Bibbins-Domingo, and Mr. Guzman: 1001 Potrero Avenue, Building 10, W13, San Francisco, CA 94110 UCSF-SFGH Box\# 1364

Dr. Goldman: Columbia University Medical Center, College of Physicians and Surgeons, 630 West 168th Street, 2nd Floor, Room 401, New York, NY 10032

Protocol: Not available

Statistical Code: Persons interested in joining the Intellectual Property Commons that is committed to improving the Model and using it for scientific purposes should contact Dr. Goldman at lgoldman@ columbia.edu.

Data: All data are publically available and sources are listed in the references of the manuscript and supplemental content.
} 
OUTCOME MEASURES-Myocardial infarction (MI), coronary heart disease (CHD) death, disability adjusted life years, costs

RESULT OF BASE-CASE ANALYSIS-All adults aged 75 and older in NHANES have a 10year risk score $>7.5 \%$. If statins have no effect on functional limitation or cognitive impairment, all primary prevention strategies would prevent MIs and CHD deaths and be cost effective. The broadest strategy, treatment of all adults aged 75-94 years would result in 8 million additional users, and prevent 105,000 (4.3\%) incident MIs and 68,000 (2.3\%) CHD deaths at an incremental cost per disability adjusted life year of $\$ 25,200$.

RESULT OF SENSITIVITY ANALYSIS-An increased relative risk of functional limitation or mild cognitive impairment in the range of 1.10 to 1.30 could offset the cardiovascular benefits.

LIMITATIONS-Limited trial evidence targeting primary prevention in adults 75 and older.

CONCLUSIONS-At effectiveness similar to trial findings, statins are projected to be costeffective for primary prevention in adults age 75-94 years; however, even a small increase in geriatric specific side effects could offset the cardiovascular benefit. Improved data on the potential benefits and harms of statins are needed to inform decision-making.

\section{INTRODUCTION}

Statins are commonly used in adults aged 75 and older. (1) Despite the widespread use of statins, the evidence for their effectiveness for primary prevention in elderly adults remains unclear, and guidelines for their use in the elderly are inconsistent. The recently published American College of Cardiology/American Heart Association (ACC/AHA) Guideline on the Treatment of Blood Cholesterol to Reduce Atherosclerotic Cardiovascular Risk in Adults gave limited recommendations for statin use for primary prevention in adults aged 75 and older, (2) noting that "few data were available to indicate an atherosclerotic cardiovascular disease event reduction benefit in primary prevention among individuals $>75$ years of age who do not have clinical atherosclerotic cardiovascular disease;" and suggesting that comorbidities, safety, and priorities of care are recommended for joint provider and patient decision-making. The American Medical Directors Association, a professional group of long-term care providers, recommended that statins not be routinely prescribed in adults aged 70 and older as a part of the American Board of Internal Medicine Choosing Wisely campaign. (3) This recommendation was based on the lack of association of high cholesterol levels and outcomes in older adults, as well as the potential for an increased risk of statinrelated adverse events, including cognitive impairment, falls, neuropathy, and muscle damage. (3)

The variation in these treatment recommendations reflects uncertainty regarding the balance between the benefits and risks of statin in older adults compared with younger adults, as well as the more limited evidence base in this population. Adults aged 75 years and older have been underrepresented in trials of statins for primary prevention, so the effectiveness of statins is less clear in this population. Results from observational studies suggest the associations between LDL-cholesterol and outcomes are attenuated in older adults. (4-7) Although the baseline risk of cardiovascular disease is increased in older adults, their life expectancy is shorter and their risks of competing mortality are greater. Finally, there has 
been concern about geriatric-specific side effects, especially functional limitation due to muscle pain, weakness, and mild cognitive impairment. (8-16)

In the presence of uncertainty regarding the risk-benefit tradeoff, computer simulations can provide estimates of the potential benefits of various treatment strategies, as well as the costs and potential risk of harms. We evaluated the population benefit and cost-effectiveness of statins in persons aged 75 years and older without a history of cardiovascular disease in the United States. This investigation was conducted using the Cardiovascular Disease Policy Model (CVDPM), a Markov model of the U.S. population. (17) We simulated the impact of statins for primary prevention based on treatment of the high risk groups identified by the ACC/AHA guidelines, the associated costs, and potential harms that could offset the potential cardiovascular benefits in the U.S. population aged 75-94 years over the next 10 years.

\section{METHODS}

\section{The Model}

The Cardiovascular Disease Policy Model (CVDPM) is an established state-transition (Markov) model of the incidence, prevalence, mortality, and cost of CHD and stroke in U.S. residents aged 35 to 94 years. (17) The present study was limited to adults aged 75-94 years. The model is composed of three components. First, the demographic-epidemiologic submodel estimates the incidence of coronary heart disease (CHD) (cardiac arrest, myocardial infarction (MI), angina, or CHD death), ischemic stroke, and death from other causes, based on age, sex, systolic blood pressure, smoking, high-density lipoprotein (HDL) cholesterol, and low-density lipoprotein (LDL) cholesterol, diabetes, body-mass index (BMI), and statin use. Second, the bridge submodel characterizes the initial CHD or stroke event and related events in the subsequent 30 days. Third, the disease-history submodel predicts the number of subsequent CHD and stroke events, revascularization procedures, and deaths among subjects with cardiovascular disease, stratified according to age, sex, and history of cardiovascular disease events. Additionally, persons may exit the model at any stage through a non-CHD, non-stroke mortality function, allowing for competing risk. Modifiable components of the model include: population distributions, risk-factor levels, risk-factor coefficients, event rates, case fatality rates, costs, and disability adjustments. (17) Hospitalized stroke and CHD costs and acute stroke rehabilitation costs were estimated using California hospital data, (18) deflated using cost to charge ratios and the ratio of the U.S. national average costs to the California average. $(19,20)$ Age and sex specific background health care costs were estimated using national data. (21) All model costs were inflated to the year 2014 using the medical component of the consumer price index. (22) All disability weights associated with the CHD and stroke event states were based on the Global Burden of Disease Study. $(23,24)$ Additional details are given in the Appendix.

\section{Simulation Inputs}

We modeled the effect of statins on LDL cholesterol based on the PROspective Study of Pravastatin in the Elderly at Risk of Vascular Disease (PROSPER) trial, a randomized, placebo controlled trial of 5,804 men and women aged 70-82 years. (25) In this trial, the 
mean LDL cholesterol lowering was 34\% for participants with an average initial LDL cholesterol of $147 \mathrm{mg} / \mathrm{dL}$, consistent with the estimated effect of a moderate dose statin in the 2013 ACA/AHA guideline. (2) We included three estimates for the effectiveness of LDL-cholesterol lowering on events. The main estimates were derived from extrapolating the age-stratified effect sizes of a $1.0 \mathrm{mmol} / \mathrm{L}$ reduction in $\mathrm{LDL}$ cholesterol from the Cholesterol Treatment Trialists' (CTT) meta-analysis. (26) We fit a regression line to the three age-strata reported in the CTT analysis ( $\leq 60$ years, $60-\leq 70$ years, and 70 and older) to estimate the effect sizes at 80 and 90 years of age. As a sensitivity analysis, we used a high estimate based on the age-pooled estimate of effect of a $1.0 \mathrm{mmol} / \mathrm{L}$ reduction in LDL cholesterol on major coronary events in the meta-analysis. We used a low estimate based on the effect size of from PROSPER for primary prevention. (25)

Statin costs were derived from the National Average Drug Acquisition Cost (NADAC) database. (27) Our main cost estimate ( $\$ 5.59$ for 30-day supply) is an average of the NADAC for the 4 moderate dose statins that are available in generic form: atorvastatin 10 $\mathrm{mg}$, simvastatin $20 \mathrm{mg}$, pravastatin $40 \mathrm{mg}$, and lovastatin $40 \mathrm{mg}$. This cost estimate is $\$ 5.00$ when indexed to 2010 dollars based on the medical component of the consumer price index. (18) Additionally, we used a low cost estimate of $\$ 4 /$ month, based on the price of generic statins from multiple discount retailers (e.g. Walmart, Target, Walgreens, etc). As a high cost estimate, we used $\$ 30 / 30$ day supply; the low and high cost estimates have been used similarly in other contemporary cost-effectiveness analyses. $(28,29)$ Adults age 65 years and older are on a median of 4 medications; therefore, we estimated the cost of an additional 0.25 physician visits per year for statin use, assuming that medication management could be covered in one visit. (30) We estimated one lipid panel per year for monitoring. $(31,32)$ Event rates for myopathy and hemorrhagic stroke were estimated as 0.001 per statin-year of use, based on the ACC/AHA guideline statement. (2)

Although there have been a number of major and minor adverse effects reported to be associated with statin use, we focused on two that are important to geriatric populations and that have generated concern in the scientific literature: functional limitation due to muscle pain and weakness, and mild cognitive impairment (MCI). (8-16) Both of these conditions are prevalent in older adults and can have substantial impact on quality of life and ability to live independently. A recent review of late life activity limitations in the U.S. reported data on participants in five nationally representative surveys. The prevalence of activity of daily living (ADL) limitation was $27 \%$ in adults $75-84$, and $45 \%$ in 85 years and older. (33) The population weighted average of these estimates is $32 \%$ for adults $75-94$ years. A wide variety of prevalence estimates for $\mathrm{MCI}$ have been reported due to the differential measures of this condition, as well as the differences between populations. A recent review reported a range of 19-28\% for the prevalence of MCI in studies of older U.S. adults; we used the average of the four U.S. studies which was $25 \%$. (34) Disability adjusted life-years for the corresponding states were calculated as 1- the disability weights reported in the Global Burden of Disease Study. (24) Since the statin-associated relative risk of these adverse effects is uncertain, we assumed no elevated risk of these adverse effects in our base case scenario. The goal of this investigation was not to evaluate the strength of the literature regarding the presence of these adverse effects, but to identify the magnitude of the potential effects that would be required to offset the cardiovascular benefit. In sensitivity analyses, we 
estimated the magnitude of this relative risk, based on the following equation: [ $\left(P_{A E} \times\right.$ $\left.\left.R R_{A E}\right)-P_{A E}\right] \times D A L Y_{A E}=D A L Y$ loss, where $\mathrm{P}_{\mathrm{AE}}=$ prevalence of the adverse effects in the population, $\mathrm{RR}_{\mathrm{AE}}=$ the relative risk of the adverse effects associated with statin use, DALY $_{\mathrm{AE}}=$ disability adjusted life-year decrement of the adverse effects, and DALY loss = the total disability adjusted life-year decrement per statin-year of use. The total disability adjusted life-year decrement per statin-year of use was varied from zero to 0.01 .

\section{Simulations}

We used the CVDPM to run a 10 year simulation of U.S. adults aged 75-94 years in 2014, followed through 2023. We modeled an open cohort which allows younger persons to age into the population. We did not model treatment among the few survivors who reached age 95 years because there are insufficient data to model cardiovascular disease in adults ages 95 years and older. We first conducted a simulation to estimate the impact of statin use for secondary prevention by modeling addition of a statin in all adults 75-94 years with a history of cardiovascular disease and currently not on a statin; we assumed the current rate of statin use for older adults without a history of cardiovascular disease. Subsequently, we conducted simulations to compare the impact of primary prevention of the three remaining groups identified in the ACC/AHA guidelines: 1) LDL-cholesterol $\_4.91 \mathrm{mmol} / \mathrm{L}$ (190 mg/ $\mathrm{dL}$ ), 2) diabetics, and 3) 10-yr cardiovascular disease risk $\geq 7.5 \%$. Ten-year cardiovascular disease risk was assessed by the 2013 ACC/AHA cardiovascular risk equation. (35) We also explored the potential impact of statins for primary prevention based on two alternative LDL-cholesterol thresholds, $\geq 4.14 \mathrm{mmol} / \mathrm{L}(160 \mathrm{mg} / \mathrm{dL})$ and $\geq 3.36 \mathrm{mmol} / \mathrm{L}(130 \mathrm{mg} / \mathrm{dL})$.

As a sensitivity analysis, we extended follow-up for an additional 10 years, from 2024-2033 to evaluate the primary prevention strategies beyond the initial inception years. We conducted sensitivity analyses of both a high and low estimate of effectiveness, as well as analyses that used a high and low cost estimate and the impact of no or one physician visit per year. We further explored the statin-associated reduction in QALYs that would be required to offset the cardiovascular disease benefit of statin use by varying the statin QALY reduction from zero to 0.01 . Finally, we used probabilistic sensitivity analyses to vary the effectiveness parameters (LDL cholesterol lowering effect of statins, and the beta-coefficient on risk of CHD for a $1 \mathrm{mg} / \mathrm{dL}$ lower $\mathrm{LDL}$ cholesterol) over the range observed in the published literature (Table 1).

Costs were calculated from the healthcare system perspective. All costs were inflated to 2014 dollars by using the Bureau of Labor Statistics Consumer Price Index for Medical Care Costs. (22) Costs and disability adjusted life-years were discounted at 3\%/year. An intervention was defined to be of high value if the cost to extend one disability adjusted lifeyears was less than $\$ 50,000$, intermediate value if the cost was $\$ 50,000$ to less than $\$ 150,000$, and low value if the cost were greater than or equal to $\$ 150,000$. (36)

\section{Role of Funding Source}

Dr. Odden was supported by the American Heart Association Western States Affiliate (11CRP7210088) and the National Institute on Aging (K01AG039387). No funding agency had any role in the study design; conduct, and reporting of data. The Institutional Review 
Board at Oregon State University determined that this study does not meet the definition of "research involving human subjects."

\section{RESULTS}

In 2014, an estimated 19 million adults in the U.S. are aged 75-94 years, and 30\% already have cardiovascular disease. Over the next 10 years with current rates of statin use, this population is projected to experience 2.5 million MIs and 3.1 million CHD deaths, and accrue costs due to cardiovascular disease of $\$ 881$ billion (Table $2 \& 3$ ). If all adults age 75 94 years with a history of cardiovascular disease who are not currently on a statin were treated with a statin over the next 10 years, approximately 53,000 MIs and 85,000 CHD deaths would be prevented, an estimated 269,000 disability adjusted life years would be gained, and the societal costs of cardiovascular disease would decline by approximately $\$ 14$ billion.

The potential impact of statins for primary prevention varies by treatment strategy. All adults age 75-94 years in NHANES have an estimated 10-year cardiovascular disease risk of $\geq 7.5 \%$, so treatment based on this risk threshold does not discriminate in this population. Adding a statin in currently untreated adults aged 75-94 years with LDL-cholesterol $\geq 4.91$ $\mathrm{mmol} / \mathrm{L}(190 \mathrm{mg} / \mathrm{dL})$ is projected to be cost-saving, but would have a minimal impact on prevention of MIs and CHD deaths in the overall population because this risk group comprises a small proportion of the population. (Table $2 \& 3$ ) Further lowering the LDLcholesterol treatment threshold to $4.14 \mathrm{mmol} / \mathrm{L}(160 \mathrm{mg} / \mathrm{dL})$, which is also projected to be cost saving, would treat substantially more elders, and the number of events prevented would increase accordingly. At a threshold of $3.36 \mathrm{mmol} / \mathrm{L}(130 \mathrm{mg} / \mathrm{dL})$, over 3 million currently untreated older adults would be treated with statins for primary prevention, and this strategy would prevent 56,000 MIs and 36,000 CHD deaths, and save 108,000 disability adjusted life-years at an estimated cost-effectiveness of $\$ 5,300$ per disability adjusted year of life compared with a threshold of $4.14 \mathrm{mmol} / \mathrm{L}(160 \mathrm{mg} / \mathrm{dL})$. Treatment of all diabetics is dominated by extension and would not be considered a cost-effective alternative to the other strategies presented. If all older adults without a history of cardiovascular disease and not currently on statins were treated, statin use in these estimated nearly 8 million new users would prevent about 105,000 MIs and 68,000 CHD deaths and save 197,000 disability adjusted life-years at an incremental cost per disability adjusted life-year of $\$ 25,200$ compared with treatment at a $3.36 \mathrm{mmol} / \mathrm{L}(130 \mathrm{mg} / \mathrm{dL})$ threshold.

When the population is stratified by age and sex, all primary prevention strategies are costsaving or of high value in men and women aged 75-84 and 85-94 years compared with secondary prevention alone. The primary prevention strategies in men are nearly all costsaving, and all strategies are of high value in women compared with secondary prevention. (Table e1) In the second decade of implementation of these statin therapy strategies (20242033), secondary prevention is projected to be no longer cost saving, but remains of high value. Additionally, the ICERs between primary prevention and secondary prevention are modestly attenuated. (Table e2) 
The benefit observed in the primary prevention strategies is sensitive to assumptions regarding the magnitude of potential harms. Based on a strategy of treating those with an LDL-cholesterol $\geq 4.91 \mathrm{mmol} / \mathrm{L}$ ( $>190 \mathrm{mg} / \mathrm{dL}$ ), the magnitude of the statin-associated disability adjusted life-year reduction necessary to offset the cardiovascular benefit would be 0.006 (Figure 1). Notably, the magnitude of a statin-associated disability adjusted life-year reduction required to offset the cardiovascular benefit would be smaller for the other primary prevention strategies. (Figure 1) This reduction translates into a relative risks that range from 1.10 to 1.24 for functional limitation and 1.12 to 1.29 for mild cognitive impairment (Table 4).

One-way sensitivity analyses demonstrate that the cost-effectiveness ratios of the primary prevention strategies are sensitive to effectiveness and cost estimates for statins. (Table 5) At a lower estimate of effectiveness or a statin cost of $\$ 30 /$ month, only treating those with an LDL-cholesterol $\geq 4.91 \mathrm{mmol} / \mathrm{L}(190 \mathrm{mg} / \mathrm{dL})$ remains of high value. In contrast, if effectiveness of statins in adults 75 years and older is comparable to that observed a younger population, or if older adults are able to obtain statins for $\$ 4 /$ month, then any primary preventions strategy would be cost-saving or of very high value.

Based on probabilistic sensitivity analyses, the findings for the primary prevention strategies appear consistent. Compared with treating those with a history of cardiovascular disease only, the treat LDL-cholesterol $\geq 4.91 \mathrm{mmol} / \mathrm{L}(190 \mathrm{mg} / \mathrm{dL})$ strategy is projected to prevent 8,000 MIs (95\% CI: 6,000,11,000), the $\geq 4.14 \mathrm{mmol} / \mathrm{L}(160 \mathrm{mg} / \mathrm{dL})$ strategy, $26,000 \mathrm{MIs}$ (95\% CI: $17,000,35,000)$, the $23.36 \mathrm{mmol} / \mathrm{L}(130 \mathrm{mg} / \mathrm{dL})$ strategy, $56,000 \mathrm{MIs}$ (95\% CI: $39,000,74,000)$, the treat DM strategy, 29,000 MIs (95\% CI: 22,000, 37,000), and the treat all strategy, 105,000 MIs (95\% CI: 75,000, 135,000). Of the primary prevention strategies, $70 \%$ of the treat LDL-cholesterol $\geq 4.91 \mathrm{mmol} / \mathrm{L}(190 \mathrm{mg} / \mathrm{dL})$ simulations, $51 \%$ of the $\geq 4.14$ $\mathrm{mmol} / \mathrm{L}(160 \mathrm{mg} / \mathrm{dL})$ simulations, $32 \%$ of the $23.36 \mathrm{mmol} / \mathrm{L}(130 \mathrm{mg} / \mathrm{dL})$ simulations, and $21 \%$ of the treat all simulations were cost saving; and $99 \%, 94 \%, 83 \%$, and $81 \%$ were of high value with a cost per disability adjusted life-year of $<\$ 50,000$.

\section{DISCUSSION}

Based on currently available data, we project that generic statins are cost-effective for primary prevention in adults aged 75-94 years, and strategies that treat a greater proportion of the population have the potential to prevent similarly higher numbers of MIs and CHD deaths. Although these findings are promising, even a small increased risk of functional limitation or cognitive impairment could offset the cardiovascular benefit. Additionally, our estimates of the value of statin use for primary prevention were susceptible to varying assumptions regarding effectiveness and cost. Due to the sensitivity of our findings to these parameters, studies to quantify both the potential benefits and harms of statin use in older adults are paramount.

The ACC/AHA guideline recommends patient/provider discussion of the potential benefits, risk of adverse effects, and patient preferences before statin initiation for primary prevention. In the absence of clear evidence, individualized treatment decision making is warranted. However, for treatment decisions that are vulnerable to variations in 
effectiveness, cost, and potential risks, more precise and reliable data on these parameters are needed to inform the decision process. Whereas effectiveness data are available through clinical trials, less systematic data exist on the potential risks of statins. Clinical trials are likely to include healthier participants compared with the general population, so the risks of an intervention in a representative patient population are uncertain. Additionally, mild-tomoderate adverse effects may be underreported in post-marketing surveillance systems intended to identify rare and serious adverse events. We focused on functional limitation due to muscle pain and weakness and mild cognitive impairment because these conditions are prevalent in older adults and can have an important and immediate impact on quality of life and independence. (8-16). Unlike previous analyses which showed that a large theoretical adverse effect would be required to counterbalance the cardiovascular benefits in the general population (28), our analysis showed that in older adults even a small adverse effect of statins on functional limitation and mild cognitive impairment could result in net harm. In our simulations, a 10-30\% increased risk of these side effects would offset the cardiovascular benefit. Our results provide strong motivation for further investigations into the incidence of side effects from statins in a diverse group of elders, including those who are frail and have complex comorbidity. Due to the sample size required to identify potential risks in a diverse population, pragmatic trials and improved post-marketing surveillance are the most promising approaches for this goal.

We focused on geriatric-specific conditions with an immediate impact on quality of life, although other potential harms and benefits have been considered. Serious side effects, including rhabdomyolisis, liver failure, and peripheral neuropathy appear to be rare, (37) and prior simulations have suggested that the rarity of these events results in a risk-to-benefit ratio that favors statin use. $(28,38,39)$ The risk of statin-associated diabetes is modest, $(37$, 39 ) and the time interval from the incidence of diabetes and clinically observable events is generally delayed and may be less concerning in older adults compared with the immediate risk of a coronary event. We also did not include the potential benefit of statins on kidney function and peripheral arterial disease because, similar to diabetes, the time interval from the incidence of these conditions until a clinically observable event is likely to be several years. Our results underscore both the tremendous potential benefit of statin use and the tenuous balance of benefits and harms, and highlight the need to both quantify and adequately account for all health effects of the use of these medications for primary prevention in older adults.

The CVDPM is tested and updated regularly to reflect changes in risk factor distributions, population estimates, risk factor associations, event rates, case-fatality rates, and costs. However, projections from any forecasting model should be viewed with caution, as there will always be unpredicted changes that can impact results. Our projections have limitations that should be considered when interpreting the findings. The primary limitation, as has been noted by professional groups, is the lack of high-quality evidence targeting primary prevention in adults 75 and older. We used the best available evidence for our simulations, and provide high and low effect sensitivity analyses. We used pharmaceutical cost data for generic statins; the cost-effectiveness of statin use may be substantially worse if older adults use newer agents that have yet to become generic. Additionally, pleiotropic effects or a 
beneficial effect of statins on kidney function or peripheral arterial disease, or a harmful effect on diabetes risks could alter our estimates of the benefit to harm ratio.

In summary, statins are projected to be cost effective for primary prevention of cardiovascular disease in a 75 to 94 year old population that derives a relative benefit similar to what was observed in randomized controlled trials, assuming a low monthly cost of statins. More research on effectiveness and potential harms in a diverse population of elders is needed to inform decision-making in populations of older adults who may be frail or have multiple chronic health conditions. Since even a modest increase in harm could offset the cardiovascular benefit in some populations, large studies of statin users are needed to identify the magnitude of any statin-associated risks. Given the growing population of older adults, the heterogeneity of their health needs and care goals, and the critical need to give patients and providers tools to make healthcare decisions that balance both potential benefits and potential harms, studies that leverage existing infrastructure may prove most useful for providing this important data in a timely manner.

\section{Supplementary Material}

Refer to Web version on PubMed Central for supplementary material.

\section{Acknowledgments}

PRIMARY FUNDING SOURCE: American Heart Association Western States Affiliate (11CRP7210088) and the National Institute on Aging (K01AG039387).

GRANT SUPPORT: This research was supported by the American Heart Association Western States Affiliate (11CRP7210088) and the National Institute on Aging (K01AG039387).

\section{References}

1. Lo-Ciganic WH, Boudreau RM, Gray SL, et al. Changes in cholesterol-lowering medications use over a decade in community-dwelling older adults. Ann Pharmacother. 2013; 47(7-8):984-92. [PubMed: 23780807]

2. Stone NJ, Robinson JG, Lichtenstein AH, et al. 2013 ACC/AHA Guideline on the Treatment of Blood Cholesterol to Reduce Atherosclerotic Cardiovascular Risk in Adults: A Report of the American College of Cardiology/American Heart Association Task Force on Practice Guidelines. Circulation. 2014; 129(25 Suppl 2):S1-45. [PubMed: 24222016]

3. AMDA. [Accessed April 22, 2014] Five Things Physicians and Patients Should Question. 2013. (http://www.amda.com/tools/choosingwisely.cfm)

4. Kronmal RA, Cain KC, Ye Z, et al. Total serum cholesterol levels and mortality risk as a function of age. A report based on the Framingham data. Arch Intern Med. 1993; 153(9):1065-73. [PubMed: 8481074]

5. Krumholz HM, Seeman TE, Merrill SS, et al. Lack of association between cholesterol and coronary heart disease mortality and morbidity and all-cause mortality in persons older than 70 years. JAMA. 1994; 272(17):1335-40. [PubMed: 7772105]

6. Schatz IJ, Masaki K, Yano K, et al. Cholesterol and all-cause mortality in elderly people from the Honolulu Heart Program: a cohort study. Lancet. 2001; 358(9279):351-5. [PubMed: 11502313]

7. Weverling-Rijnsburger AW, Blauw GJ, Lagaay AM, et al. Total cholesterol and risk of mortality in the oldest old. Lancet. 1997; 350(9085):1119-23. [PubMed: 9343498]

8. Muldoon MF, Ryan CM, Sereika SM, et al. Randomized trial of the effects of simvastatin on cognitive functioning in hypercholesterolemic adults. Am J Med. 2004; 117(11):823-9. [PubMed: 15589485] 
9. Padala KP, Padala PR, Potter JF. Statins: a case for drug withdrawal in patients with dementia. J Am Geriatr Soc. 2010; 58(6):1214-6. [PubMed: 20722868]

10. Wagstaff LR, Mitton MW, Arvik BM, et al. Statin-associated memory loss: analysis of 60 case reports and review of the literature. Pharmacotherapy. 2003; 23(7):871-80. [PubMed: 12885101]

11. Schiattarella GG, Perrino C, Magliulo F, et al. Statins and the elderly: recent evidence and current indications. Aging Clin Exp Res. 2012; 24(3 Suppl):47-55. [PubMed: 23160507]

12. Scott D, Blizzard L, Fell J, et al. Statin therapy, muscle function and falls risk in communitydwelling older adults. QJM. 2009; 102(9):625-33. [PubMed: 19633029]

13. Joy TR, Hegele RA. Narrative review: statin-related myopathy. Ann Intern Med. 2009; 150(12): 858-68. [PubMed: 19528564]

14. Bruckert E, Hayem G, Dejager S, et al. Mild to moderate muscular symptoms with high-dosage statin therapy in hyperlipidemic patients--the PRIMO study. Cardiovasc Drugs Ther. 2005; 19(6): 403-14. [PubMed: 16453090]

15. Lee DS, Markwardt S, Goeres L, et al. Statins and Physical Activity in Older Men: The Osteoporotic Fractures in Men Study. JAMA Intern Med. 2014

16. Sathasivam S. Statin induced myotoxicity. Eur J Intern Med. 2012; 23(4):317-24. [PubMed: 22560377]

17. Weinstein MC, Coxson PG, Williams LW, et al. Forecasting coronary heart disease incidence, mortality, and cost: the Coronary Heart Disease Policy Model. Am J Public Health. 1987; 77(11): 1417-26. [PubMed: 3661794]

18. California Office of Statewide Health and Planning. California Patient Discharge Data January 1December 31, 2000, Public Version A-24 [CD-ROM]. Sacramento: 2000.

19. Statistical Abstract of the United States Bureau of the Census. Washington, D.C: Government Printing Office; 1998. Average cost to community hospitals per patient, by state (Table 204); p. 136

20. [Accessed June, 2010] California Office of Statewide Health and Planning Hospital financial data for cost to charge ratio, CA inpatient discharge data hospital annual financial data, pivot profiles 1999-2000. 2008. (www.oshpd.ca.gov/HID/Products/Hospitals/AnnFinanData/PivotProfles/ default.asp)

21. CMMS. Personal Health Care Spending by Type of Spending, Age Group, and Source of Payment Distirbution, Calendar year 1999. Baltimore, MD: 2000. (www.cms.hhs.gov/ NationalHealthExpendData/downloads/agetables.pdf) [Accessed June, 2010]

22. Bureau of Labor Statistics. Consumer Price Index. Washington, D.C: 2014. (www.bls.gov/CPI/) [Accessed April, 2014]

23. Murray CJ, Vos T, Lozano R, et al. Disability-adjusted life years (DALYs) for 291 diseases and injuries in 21 regions, 1990-2010: a systematic analysis for the Global Burden of Disease Study 2010. Lancet. 2012; 380(9859):2197-223. [PubMed: 23245608]

24. Salomon JA, Vos T, Hogan DR, et al. Common values in assessing health outcomes from disease and injury: disability weights measurement study for the Global Burden of Disease Study 2010. Lancet. 2012; 380(9859):2129-43. [PubMed: 23245605]

25. Shepherd J, Blauw GJ, Murphy MB, et al. Pravastatin in elderly individuals at risk of vascular disease (PROSPER): a randomised controlled trial. Lancet. 2002; 360(9346):1623-30. [PubMed: 12457784]

26. Mihaylova B, Emberson J, Blackwell L, et al. The effects of lowering LDL cholesterol with statin therapy in people at low risk of vascular disease: meta-analysis of individual data from 27 randomised trials. Lancet. 2012; 380(9841):581-90. [PubMed: 22607822]

27. CMMS. [Accessed 9/30/14 2014] National Average Drug Acquisition Cost (NADAC). 2014. (http://www.medicaid.gov/medicaid-chip-program-information/by-topics/benefits/prescriptiondrugs/pharmacy-pricing.html)

28. Lazar LD, Pletcher MJ, Coxson PG, et al. Cost-effectiveness of statin therapy for primary prevention in a low-cost statin era. Circulation. 2011; 124(2):146-53. [PubMed: 21709063]

29. Pletcher MJ, Pignone M, Earnshaw S, et al. Using the coronary artery calcium score to guide statin therapy: a cost-effectiveness analysis. Circ Cardiovasc Qual Outcomes. 2014; 7(2):276-84. [PubMed: 24619318] 
30. National Center for Health Statistics. [Accessed 2012] National Health and Nutrition Examination Survey, 2009-2012. (http://wwwn.cdc.gov/nchs/nhanes/search/nhanes09_10.aspx \& http:// wwwn.cdc.gov/nchs/nhanes/search/nhanes11_12.aspx)

31. CMMS. [Accessed April 4th, 2014] National Physician Fee Schedule. 2010B. (http:// www.cms.gov/apps/physician-fee-schedule/search/search-criteria.aspx)

32. CMMS. [Accessed April 4th, 2014] Clinical Lab Fee Schedule. 2010B. (http://www.cms.gov/ Medicare/Medicare-Fee-for-Service-Payment/ClinicalLabFeeSched/clinlab.html)

33. Freedman VA, Spillman BC, Andreski PM, et al. Trends in late-life activity limitations in the United States: an update from five national surveys. Demography. 2013; 50(2):661-71. [PubMed: 23104207]

34. Ward A, Arrighi HM, Michels S, et al. Mild cognitive impairment: disparity of incidence and prevalence estimates. Alzheimers Dement. 2012; 8(1):14-21. [PubMed: 22265588]

35. Goff DC Jr, Lloyd-Jones DM, Bennett G, et al. 2013 ACC/AHA Guideline on the Assessment of Cardiovascular Risk: A Report of the American College of Cardiology/American Heart Association Task Force on Practice Guidelines. Circulation. 2014; 129 (25 Suppl 2):S49-73. [PubMed: 24222018]

36. Anderson JL, Heidenreich PA, Barnett PG, et al. ACC/AHA Statement on Cost/Value Methodology in Clinical Practice Guidelines and Performance Measures: A Report of the American College of Cardiology/American Heart Association Task Force on Performance Measures and Task Force on Practice Guidelines. Circulation. 2014

37. Law M, Rudnicka AR. Statin safety: a systematic review. Am J Cardiol. 2006; 97(8A):52C-60C.

38. Pletcher MJ, Lazar L, Bibbins-Domingo K, et al. Comparing impact and cost-effectiveness of primary prevention strategies for lipid-lowering. Ann Intern Med. 2009; 150(4):243-54. [PubMed: 19221376]

39. Ridker PM, Pradhan A, MacFadyen JG, et al. Cardiovascular benefits and diabetes risks of statin therapy in primary prevention: an analysis from the JUPITER trial. Lancet. 2012; 380(9841):56571. [PubMed: 22883507] 


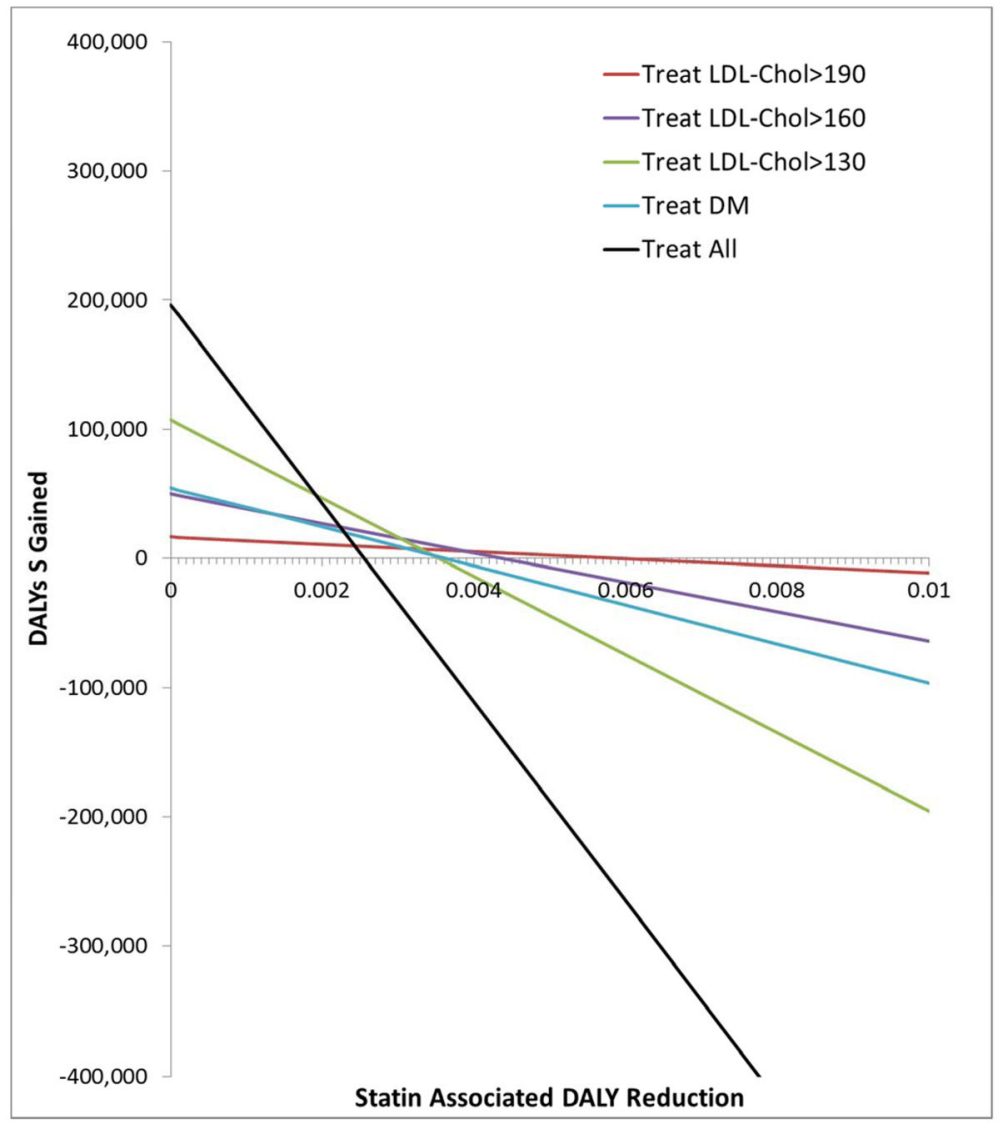

Figure 1.

Sensitivity analysis of magnitude of statin associated disability adjusted life-year reduction that would be needed to offset the cardiovascular benefit. The value of the statin-associated disability adjusted life-year reduction at which the lines cross the $\mathrm{x}$-axis is the magnitude needed to offset the cardiovascular benefit and result in no net disability adjusted life-years gained. 


\section{Table 1}

Inputs for simulation

\begin{tabular}{|c|c|c|c|}
\hline Input & & Effect Size & Reference \\
\hline \multicolumn{4}{|l|}{ EFFECTIVENESS } \\
\hline LDL-C Lowering from statins & & $\begin{array}{l}34 \% \text { (95\% CI: } 20.4 \\
47.6)\end{array}$ & $(2,25)$ \\
\hline \multicolumn{4}{|l|}{ Beta-Coefficient, per mg/dL of LDL-C } \\
\hline & Stroke & 0 & (25) \\
\hline & CHD Base Case & $\begin{array}{l}0.004 \text { (SD 0.0006) } \\
0.003 \text { (SD 0.0006) }\end{array}$ & (26) \\
\hline & CHD Low Sensitivity & 0.001 & (25) \\
\hline & CHD High Sensitivity & 0.007 & (26) \\
\hline \multicolumn{4}{|l|}{ COST } \\
\hline \multirow[t]{3}{*}{ Medication Costs } & Base Case & $\$ 5 / 30 /$ days & (27) \\
\hline & Low Sensitivity & $\$ 4 / 30$ days & (29) \\
\hline & High Sensitivity & $\$ 30 / 30$ days & (29) \\
\hline Physician Visit & 1 every 4 years & $\$ 67$ & (31) \\
\hline Lipid Panel & & $\$ 19$ & (32) \\
\hline Creatine Kinase & 3 tests per myopathy case & $\$ 9.33$ & (32) \\
\hline Hospitalization from stroke & & $\$ 15,000$ & $(18-20)$ \\
\hline \multicolumn{4}{|l|}{ ADVERSE EFFECTS } \\
\hline Myopathy (events per statin- year) & & 0.001 & (2) \\
\hline Hemorrhagic Stroke (events per statin-year) & & 0.001 & (2) \\
\hline Time to recover from myopathy & & 2 Months & Clinical judgment \\
\hline QALY Reduction of Myopathy & (musculoskeletal problems, severe) & 0.606 & (24) \\
\hline QALY Reduction of Stroke & (moderate plus cognition problems) & 0.312 & (24) \\
\hline \multicolumn{4}{|l|}{ GERIATRIC-SPECIFIC } \\
\hline \multicolumn{4}{|l|}{ ADVERSE EFFECTS } \\
\hline Statin Associated Disability & Base Case & 0 & Clinical judgment \\
\hline $\begin{array}{l}\text { Adjusted Life-Year Reduction due to Functional } \\
\text { Limitation or Mild Cognitive Impairment }\end{array}$ & Sensitivity & $0-0.01$ & Clinical judgment \\
\hline Prevalence of Functional Limitation & & $32 \%$ & (33) \\
\hline $\begin{array}{l}\text { Disability Adjusted Life-Year Reduction of Functional } \\
\text { Limitation }\end{array}$ & & 0.076 & (24) \\
\hline Prevalence of Mild Cognitive Impairment & & $25 \%$ & (34) \\
\hline $\begin{array}{l}\text { Disability Adjusted Life Year Reduction of Mild } \\
\text { Cognitive Impairment }\end{array}$ & & 0.082 & (24) \\
\hline 10-YEAR CVD RISK & & $>7.5 \%$ for all $\geq 75$ years & (35) \\
\hline
\end{tabular}

Abbreviations: LDL-C = low-density lipoprotein cholesterol; $\mathrm{CHD}=\mathrm{CHD}$ 


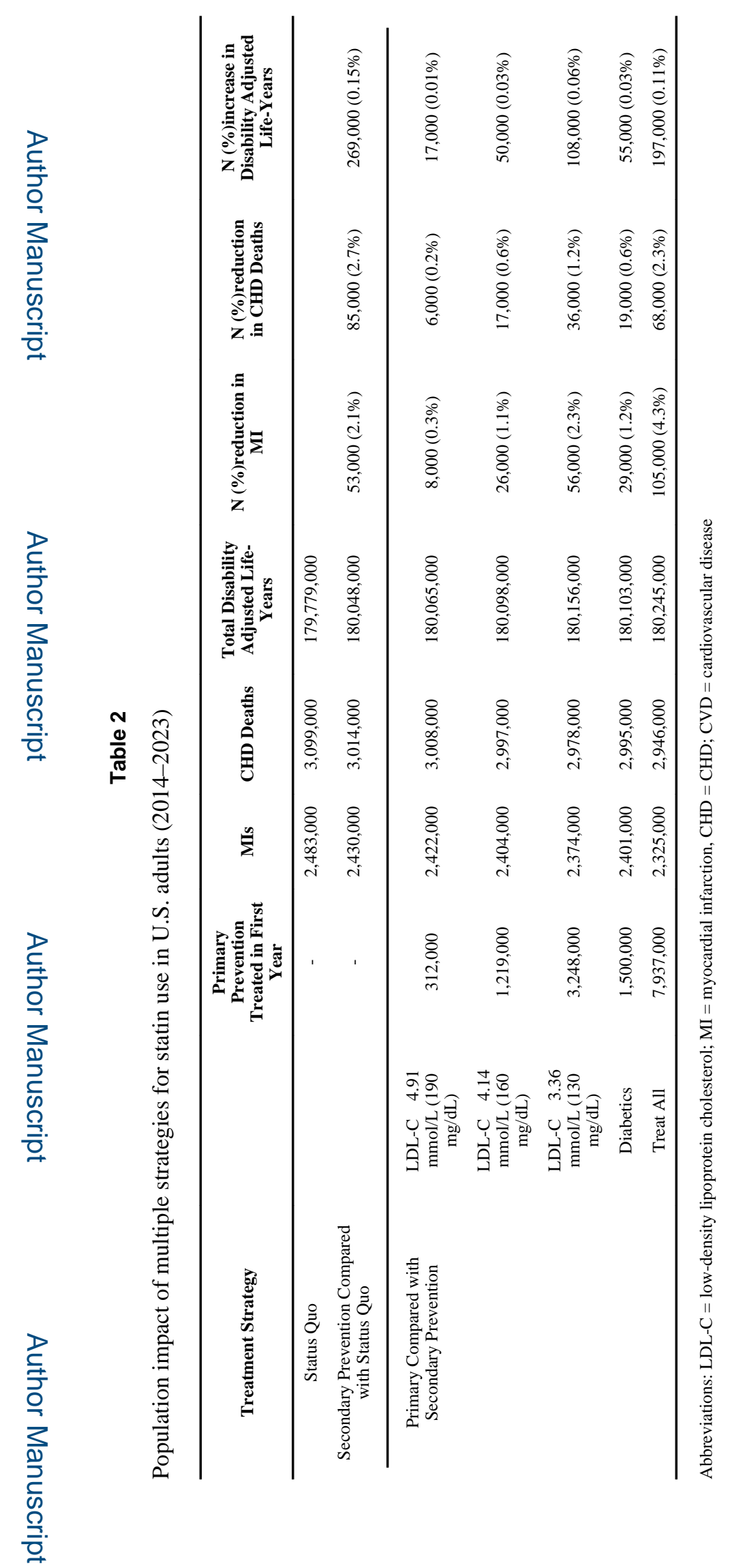

Ann Intern Med. Author manuscript; available in PMC 2016 April 21. 


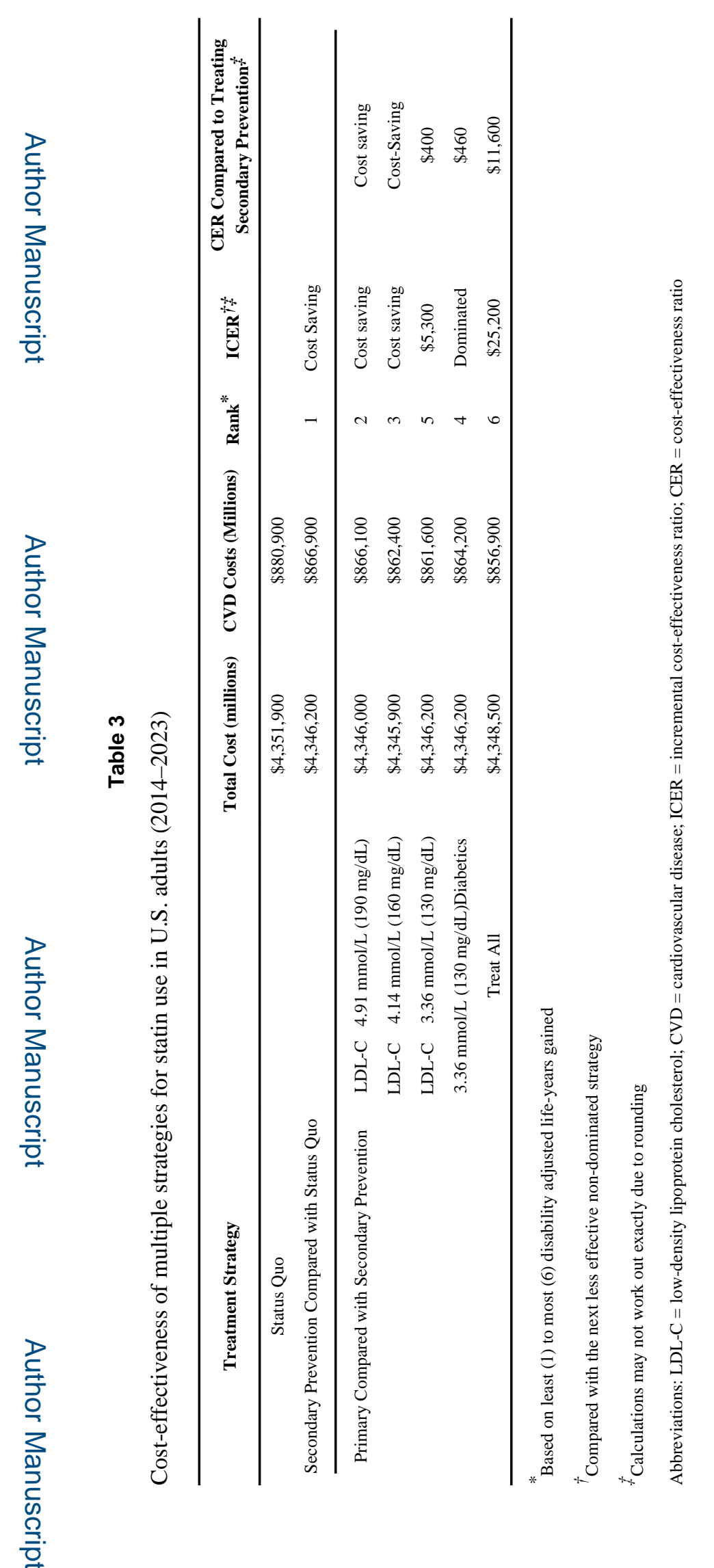

Ann Intern Med. Author manuscript; available in PMC 2016 April 21. 


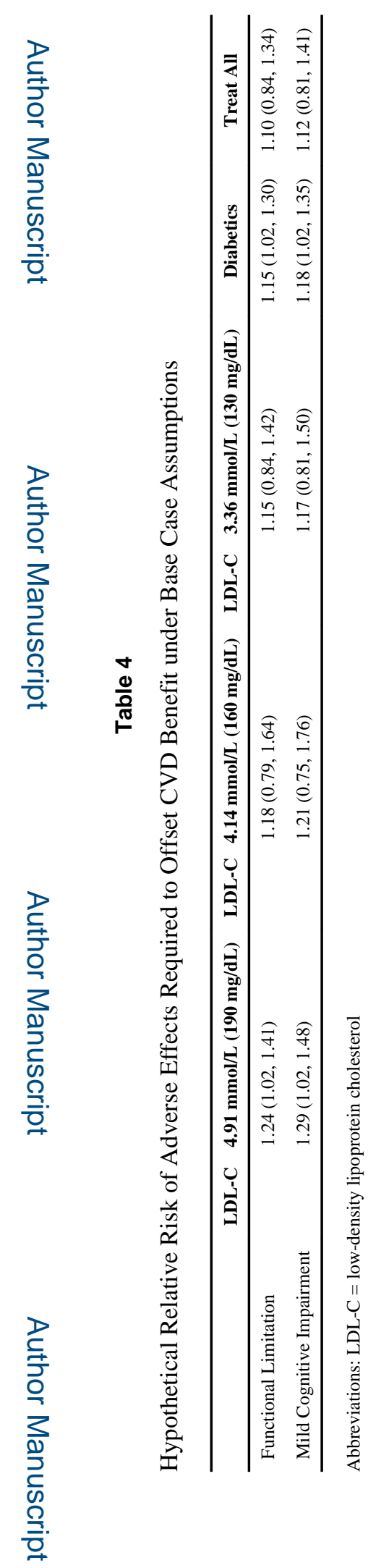

Ann Intern Med. Author manuscript; available in PMC 2016 April 21. 


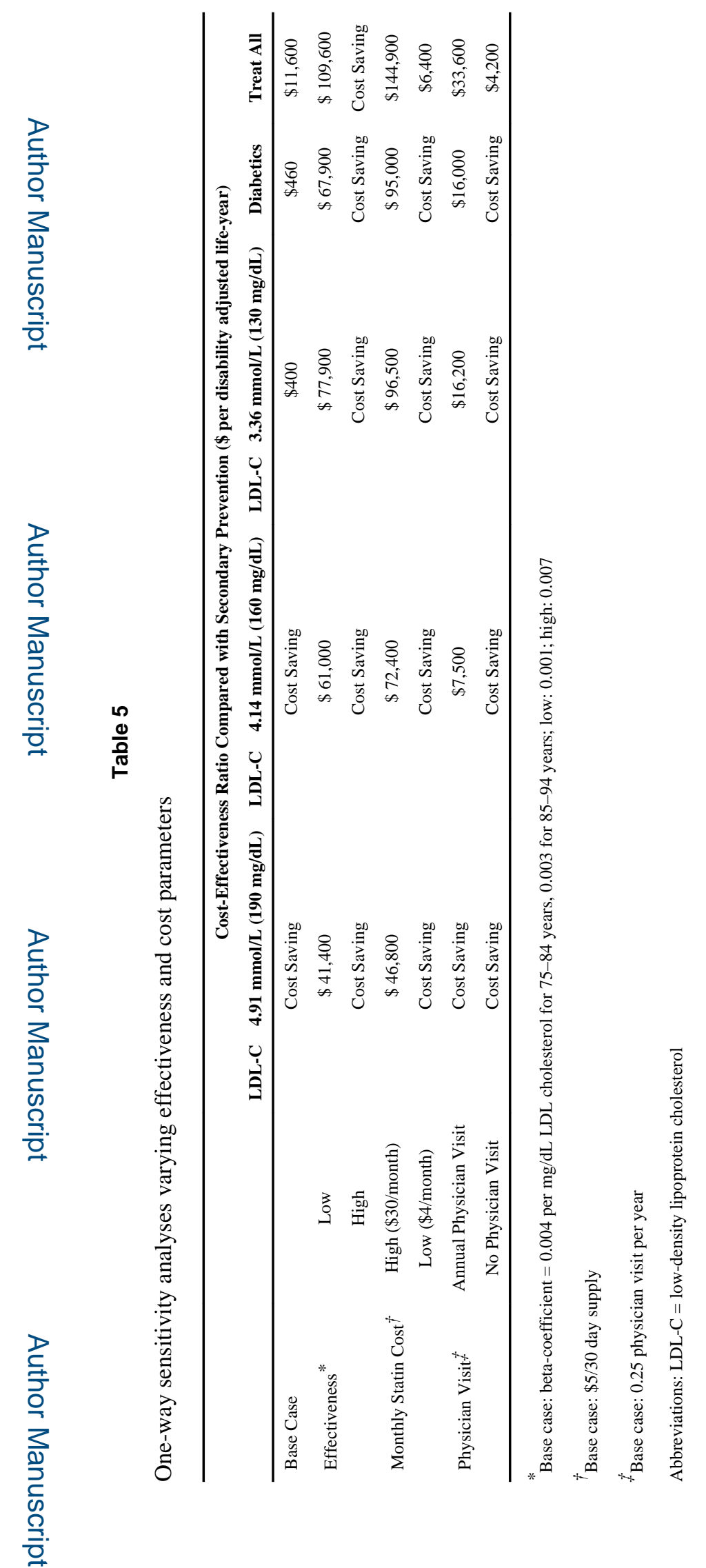

Ann Intern Med. Author manuscript; available in PMC 2016 April 21. 